\title{
COVID-19 PANDEMIC AND CHANGING PRACTICES IN SPINAL SURGERY
}

\author{
๑ Riza Mert ÇETIK, ๑ H. Gökhan DEMIRKIRAN \\ Hacettepe University Hospital, Clinic of Orthopaedics and Traumatology, Ankara, Turkey
}

The novel Coronavirus disease-2019 (COVID-19), which was identified in December 2019, has quickly evolved into a pandemic, thereby forcing spine surgeons to modify their daily practice. Several articles and guidelines have been published on how to manage daily routines during the pandemic.

Neurologic deficits, spinal instability and spinal infections are generally considered as emergencies and treated immediately. Every patient who is scheduled to undergo surgery must first be screened for signs and symptoms of the disease, and diagnostic tests must be conducted on suspected and high-risk patients. In addition, precautions must be taken in the operating room to minimise the risk of disease transmission.

In regions where the disease has started to decline, a gradual return to the normal routine activities is being considered. Surgeons must be aware of the local circumstances and elective surgeries can only be resumed when the safety of patients and healthcare personnel are no longer at risk. In this review article, we aimed to combine the data with our experience and help spine surgeons in adapting to the current situation.

Keywords: SARS-CoV-2, COVID-19, spine surgery, triaging, coronavirus, pandemic

\section{INTRODUCTION}

On December 2019, the whole world witnessed the emergence of a novel RNA betacoronavirus in Wuhan, which is the capital city of the Hubei province of China ${ }^{(1)}$. This virus was later called severe acute respiratory syndorme-Coronavirus-2(SARS-COV-2) SARS-CoV-2, and the disease caused by this microorganism is referred to as the novel coronavirus disease-2019 (COVID-19). This outbreak rapidly evolved into a global pandemic, and as of May 29th 2020 it had spread across 216 countries with over $5,700,000$ confirmed cases and 350,000 confirmed deaths ${ }^{(2)}$.

Turkey's first case of COVID-19 was reported on March $11^{\text {th }}$, 2020. The country's response was swift and every health institution applied adaptive measures to prevent the virus from spreading. On March $17^{\text {th }}, 2020$, all elective surgical procedures were suspended by an official directive from the Ministry of Health, and in the following days, doctors and nurses from almost every department were allocated to COVID-19 clinics and wards.

Spine surgeons remembered their duties as general practitioners of medicine and were involved in the care of COVID-19. Postponing elective procedures made it possible to relocate healthcare providers to frontline duties, but it also helps in preserving the valuable hospital resources for the care of the critically-ill, such as personal protective equipment (PPE), intensive care unit beds, ventilators and blood products. Some hospitals are strictly reserved for COVID-19 cases, but many others provide care for urgent and emergent conditions at the same time. Spinal surgeons working in these hospital's are often expected to triage the patients and perform emergent surgeries to prevent impairment. The changing practices leads to a confusion among surgeons; lack of prior experience and guidelines forced us to determine our own standards for the care of our patients; in a study on spine surgeons worldwide, $94.7 \%$ of our colleagues reported a need for international guidelines for the management of patients during this pandemic ${ }^{(3)}$. Every aspect of spinal surgery, from diagnosis to postoperative care changed during this unprecedented pandemic. The duration of this pandemic is currently unclear, and even though the number of active cases is declining worldwide, surgeons need to be prepared for upcoming outbreaks. The purpose of this article is to help guide spine surgeons on how to successfully triage patients, minimise the risk of transmission before, during and after surgery, and when to resume with elective procedures safely.

\section{Triaging in Spinal Surgery}

Spine surgeons routinely perform emergent and urgent surgical procedures for conditions such as traumatic and oncologic

Address for Correspondence: H. Gökhan Demirkıran, Hacettepe University Hospital, Clinic of Orthopaedics and Traumatology, Ankara, Turkey E-mail: hgokhand@yahoo.com Received: 05.06.2020 Accepted: 14.07.2020

ORCID ID: orcid.org/0000-0001-5612-5599 
pathologies, to prevent neurologic impairment and permanent disabilities. It is common sense that emergent procedures should not be postponed if the medical institution's resources permit it. There are also certain elective procedures for conditions such as degenerative diseases and deformities, which can be postponed for a couple of months. However, the grey-zone between emergent and elective is wide, and surgeons are often faced with the difficulty of making this decision during the pandemic. In an attempt to provide a solution, different medical communities came up with guidelines, like the American College of Surgeons, the North American Spine Society (NASS) and the Rothman Institute ${ }^{(4-6)}$. Institutional experiences are also shared by spine surgeons across the world ${ }^{(7-10)}$.

In our hospital, we mainly adhered to the triaging guideline recommended by the NASS (Table 1$)^{(5)}$. The Rothman Institute guideline also contains valuable information, although it presumes the availability of two separate facilities as the hospital and the ambulatory surgery centre ${ }^{(6)}$. To summarise our practice, we generally considered neurologic deficits, spinal instability and spinal infections as emergencies, and surgical treatment was performed. For other cases, conservative treatment was preferred whenever possible. Certain other factors should also be considered when making the decision, such as;

- Guidelines do not apply to every patient and surgeons must be ready to take decisions on a case-by-case basis.

- Surgeons must be aware of the current situation and available resources in the hospital. Daily updates must be made considering the hospital's operative capacity.

- The period of delay for the postponed surgeries is not predetermined. It should be kept in mind that the clinical situation of the patients may change and neurologic deterioration may occur; therefore, follow-up visits can be organised accordingly. Telemedicine is currently being tried by some institutions for this purpose ${ }^{(11)}$.

- For emergency surgical procedures, efforts must be made to utilise minimally-invasive approaches, if possible, in order to keep the hospitalisation period at a minimum.

\section{Hospitalisation and Operating Room Precautions for Spinal Surgery}

When a patient is triaged to undergo surgery, necessary precautions must be taken in order to minimise the risk of transmitting the disease, from the onset of hospitalisation until discharge. Patients must be kept in single rooms, and companions must not be allowed if possible. Patients must wear a surgical mask at all times, and all healthcare workers must wear the necessary PPE.

Every patient is questioned and examined for fever, respiratory symptoms and history of contact with diagnosed/suspected cases of COVID-19. Every healthcare professional must keep in mind that up to $80 \%$ of patients may be asymptomatic and still contagious $^{(12)}$. Before surgery, patients are classified into one of these three risk categories ${ }^{(13)}$ :

Confirmed/suspected, high-risk and low-risk. In our institution, polymerase chain reaction $(P C R)$ screening is not routinely performed; only those who are confirmed/suspected or in the high-risk group are tested. When a risk factor is present, surgery should be delayed until the test results are release, if the surgical emergency permits.

If a patient is diagnosed positive (or if there is suspicion when the surgery cannot be delayed until the test results come out), the surgery must be performed in a room reserved for COVID-19

Table 1. Triaging guideline during the COVID-19 pandemic, adapted from the North American Spine Society

\begin{tabular}{|c|c|c|}
\hline Category & Presentation & Recommendation \\
\hline Emergent & $\begin{array}{l}\text { - Progressive or severe neurologic deficit due to neurologic } \\
\text { compression from any cause } \\
\text { - Spinal instability at risk of causing neurologic deficit } \\
\text { - Epidural abscess } \\
\text { - Postoperative surgical site infections }\end{array}$ & $\begin{array}{l}\text { Do not postpone the surgical } \\
\text { treatment }\end{array}$ \\
\hline Urgent & $\begin{array}{l}\text { - Cervical or thoracic myelopathy due to spinal stenosis, with recent } \\
\text { progression } \\
\text { - Spinal infection that does not respond to medical treatment } \\
\text { - Persistent significant neurologic deficit due to neurologic } \\
\text { compression, with or without deformity } \\
\text { - Spinal pathologies causing intractable pain that result in emergency } \\
\text { department presentation, causing severe functional limitation and/or } \\
\text { excessive opioid use despite non-surgical attempts at treatment }\end{array}$ & $\begin{array}{l}\text { Proceed with surgery/procedure if } \\
\text { the local situation and resources } \\
\text { allow. }\end{array}$ \\
\hline Elective & $\begin{array}{l}\text { - Spinal pathologies where pain and dysfunction can be reasonably } \\
\text { managed without surgical intervention } \\
\text { - Spinal deformity (scoliosis/kyphosis) correction } \\
\text { - Pseudoarthrosis } \\
\text { - Symptomatic hardware }\end{array}$ & Postpone the surgery \\
\hline
\end{tabular}


turkishspine

patients, preferably in the corner of the operating complex ${ }^{(14)}$. Negative pressure environment is protective against aerosol spread, and it should be kept in mind that many OR's have positive pressure setups.

SARS-CoV-2 spreads through aerosols, and known aerosol generating procedures include intubation, extubation, bag masking and electrocautery of blood and other body fluids(4). Even the smoke produced by the electrosurgical equipment were shown to transmit certain viruses ${ }^{(15)}$; therefore, the amount of personnel in the room before, during and after the surgery of COVID-19 patients should be kept at a minimum.

Wearing full PPE during the surgery of COVID-19 patients is of utmost importance. The necessary PPE include a well-fitting N95 mask, goggles or face shield, splash resistant gown and foot covers. In our hospital, surgical hoods with powered air purifying respirators are also used for the surgery of diagnosed/ suspected patients (Figure 1).

In collaboration with the department of anaesthesiology, certain rules were determined for every surgical procedure, including low-risk and negative patients:

- $\quad$ All the personnel in the operating room (OR) must wear the proper PPE's

- $\quad$ Every patient will be intubated with a video laryngoscope if possible

- $\quad$ During intubation, only the anaesthesiology team will be present in the room, and surgeons and other personnel will enter the room at least 10 minutes after the intubation

- Before the extubation, surgeons and other personnel should clear the room, and will re-enter at least 10 minutes after the process.

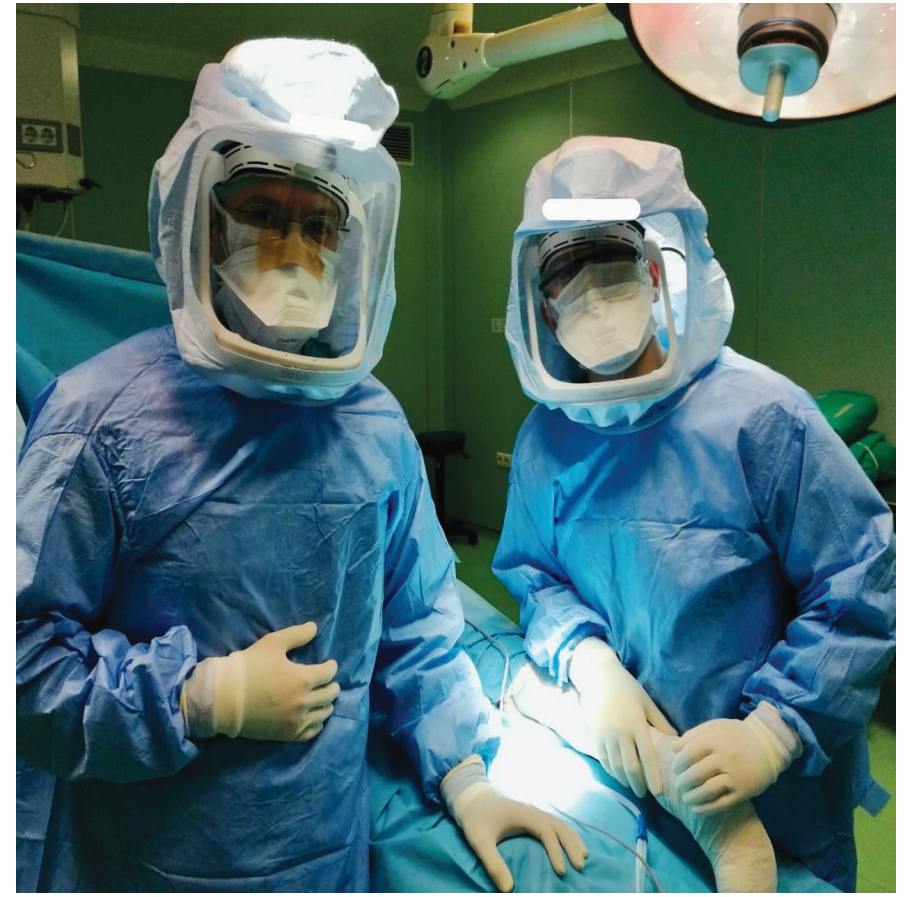

Figure 1. Surgical hoods with a powered air purifying respirator, used during the surgeries of diagnosed/suspected cases

\section{Resuming Elective Spinal Surgery}

As the COVID-19 pandemic has begun to decline in many countries, elective surgical procedures are slowly being reintroduced into our practice. Spinal surgeons must evaluate the current situation in their institutions and countries, and thus decide on the appropriate timing for this.

The Centres for Medicare and Medicaid Services has issued recommendations for a gradual return to elective surgical procedures $^{(16)}$, followed by other communities such as the American Academy of Orthopaedic Surgeons ${ }^{(17)}$. Generally, every surgeon must consider certain key points before resuming these surgeries:

- $\quad$ Safety of patients is of first priority, followed by the safety of healthcare personnel,

- Institutional rules must adhere to local government policies and regulations,

- The local COVID-19 diagnosis rate is declining, preferably for at least 14 days,

- The hospital must have adequate facilities and resources to properly screen every patient, and perform a test (PCR or antibody) whenever necessary,

- All healthcare personnel must be routinely screened,

- Non-COVID-19 patients and COVID-19 patients must be housed in separate facilities,

- The hospital must have adequate resources (personnel, PPE, facilities etc.) to quickly respond to an unexpected increase in the number of COVID-19 cases,

- $\quad$ Patients with comorbidities and those within the older age group may need to be postponed, until the new standards of care are established.

\section{DISCUSSION}

The current pandemic has forced us to change every aspect of our daily practice, and for an unknown period of time. Every one of us has learned different lessons and it is now more important than ever to share every bit of experience with each other and to help in adapting to the changing needs of the community. Treating patients with emergent and urgent spinal pathologies, while preventing the disease from spreading, is a challenging task. Since the beginning of the pandemic, distinguishing these cases from the electives has been the most difficult task. Considering the lack of studies in the literature, we combined our experience with guidelines by certain institutions ${ }^{(4-6)}$. The information we shared in this review article will be a guide to help surgeons through the triaging process.

Further precautions are also necessary in the hospital and OR to maintain a safe environment. A study reported that over $15 \%$ of spine surgeons who underwent viral testing resulted positive ${ }^{(3)}$, which emphasises the importance of personal protection.

Some institutions are on the brink of returning to a normal practice, but we should always keep in mind that another wave might be waiting around the corner. We do not know what the 
near future will bring, but the experience we gathered so far will certainly help us through.

\section{Ethics}

Peer-review: Externally and internally peer-reviewed.

\section{Authorship Contributions}

Surgical and Medical Practices: R.M.Ç., H.G.D., Concept: R.M.Ç., H.G.D., Design: R.M.Ç., H.G.D., Data Collection or Processing: R.M.Ç., Analysis or Interpretation: R.M.Ç., H.G.D., Literature Search: R.M.Ç., H.G.D., Writing: R.M.Ç., H.G.D.

Conflict of Interest: No conflict of interest was declared by the authors.

Financial Disclosure: The authors declared that this study received no financial support.

\section{REFERENCES}

1. Lu R, Zhao X, Li J, Niu P, Yang B, Wu H, et al. Genomic characterisation and epidemiology of 2019 novel coronavirus: implications for virus origins and receptor binding. Lancet. 2020;395:565-74.

2. World Health Organization (WHO) Coronavirus disease (COVID-19) outbreak situation: https://www.who.int/emergencies/diseases/ novel-coronavirus-2019, 2020.

3. Louie PK, Harada GK, McCarthy MH, Germscheid N, Cheung JPY, Neva $\mathrm{MH}$, et al. The Impact of COVID-19 Pandemic on Spine Surgeons Worldwide. GSJ. 2020:10;1-19.

4. American College of Surgeons. Clinical issues and guidance. Surgical care and coronavirus disease 2019 (COVID-19). https://www.facs. org/about-acs/covid-19/information-for-surgeons, 2020.

5. North American Spine Society (NASS) Guidance document on Elective, Emergent and Urgent Spine Procedures and Treatments. https://www.spine.org/COVID-19, 2020
6. Donnally CJ, Shenoy K, Vaccaro AR, Schroeder GD, Kepler CK. Triaging Spine Surgery in the COVID-19 Era. Clin Spine Surg. 2020;33:129-30.

7. Meyer M, Prost S, Farah K, Denis JB, Dufour H, Blondel B, et al. Spine Surgical Procedures during Coronavirus Disease 2019 Pandemic: Is It Still Possible to Take Care of Patients? Results of an Observational Study in the First Month of Confinement. Asian Spine J. 2020;14:336-40.

8. Giorgi PD, Villa F, Gallazzi E, Debernardi A, Schiro GR, Crisa FM, et al. The management of emergency spinal surgery during the COVID-19 pandemic in Italy. Bone Joint J. 2020:102-B:671-6.

9. Ghogawala Z, Kurpad S, Falavigna A, Groff MW, Sciubba DM, Wu JC, et al. Editorial. COVID-19 and spinal surgery. J Neurosurg Spine. 2020:1-3.

10. El Helou A. Spine Surgery in Atlantic Canada in the COVID-19 era: lessons learned so far. Spine J. 2020.

11. Yoon JW, Welch R, Alamin T, Lavelle WF, Cheng I, Perez-Cruet M, et al. Remote Virtual Spinal Evaluation in the Era of COVID-19. International Journal of Spine Surgery. 2020.

12. Day M. COVID-19: identifying and isolating asymptomatic people helped eliminate virus in Italian village. BMJ. 2020;368:m1165.

13. Liu Z, Zhang Y, Wang $X$, Zhang D, Diao D, Chandramohan K, et al. Recommendations for Surgery During the Novel Coronavirus (COVID-19) Epidemic. Indian J Surg. 2020:1-5.

14. Ti LK, Ang LS, Foong TW, Ng BSW. What we do when a COVID-19 patient needs an operation: operating room preparation and guidance. Can J Anaesth. 2020;67:756-8.

15. Johnson GK, Robinson WS. Human immunodeficiency virus-1 (HIV-1) in the vapors of surgical power instruments. J Med Virol. 1991;33:47-50.

16. Centers for Medicare \& Medicaid Services (CMS). Re-opening Facilities to Provide Non-emergent Non-COVID-19 Healthcare: Phase I. https://www.cms.gov/files/document/covid-flexibility-reopenessential-non-covid-services.pdf, 2020.

17. American Academy of Orthopaedic Surgeons (AAOS). Navigating the COVID-19 Pandemic. https://www.aaos.org/globalassets/about/ covid-19/, 2020. 